\title{
Integration of traffic flow relations in a simulation environment
}

\author{
M. Reinthaler \& J. Zajicek \\ Arsenal research, Giefinggasse 2, 1210 Vienna, Austria
}

\begin{abstract}
An essential part in modelling traffic systems is to analyse and map the traffic demand. Taking one traffic mode and defined time periods into consideration the traffic demand is defined by traffic flows. Establishing traffic flow and origindestination (OD) relations is based on different data sources and methods. The technology employed in order to make use of mobile traffic participants as sensors is referred to as Floating Car Technology. The navigation system, the mobile phone or the car itself can serve as the mobile sensor to supply Floating Car Data (FCD). Arsenal research has done several projects and analysis on FCD and is cooperating with taxi fleets to process FCD for additional benefits.

One field of application is setting up OD matrices for integration in simulation environments. The calculation is based on FCD for a defined period. The system establishes the geographical relation to the traffic model and the chronological context to defined scenarios. The publication describes the method and a field trial of the system with available taxi data to find origin-destination relations for a microscopic model. The evaluation of results in quality and quantity and the integration of calculated traffic demand in a simulation environment are specified.
\end{abstract}

Keywords: traffic modelling, traffic simulation, floating car data, traffic demand, traffic flow, origin destination matrices.

\section{Introduction}

The increasing amount of traffic data opens new possible fields of application. Satellite-, network- and vehicle-based systems are in use to gather information about traffic situations. In contrast to the high costs to set up sensor networks on the infrastructure, the Floating Car Technology is an alternative with low 
investments. The traffic participants act like a sensor and are floating within the traffic. Measuring the position can be based on different technologies, such as satellite based systems (GPS) or the cellular phone network (GSM) [4].

The choice of technology affects the accuracy of the position data. Furthermore the additional information (e.g. direction of driving or speed) and the duration between measurements correspond to the technology. Vehicles are not equipped to collect traffic data but to optimize the daily business of the organization. Typically fleets with management systems are from the fields of transport, taxi fleets, action forces or public services. The collected Floating Car Data (FCD) can be used as an additional high quality data source in traffic management systems [3].

\section{Modelling the traffic demand}

The process of modelling the traffic demand is divided into four sub processes [1]. The division of the planning area into traffic zones (or traffic districts) is a precondition for the modelling process. A zone can both produce traffic and attract traffic. Therefore the first step, the Generation of traffic, consists of two models, for the origin and destination traffic, without reference to the second location. Modelling the distribution of traffic considers both the origin and the corresponding destination. The origin-destination (OD) Matrix describes the traffic flows between all zones in the planning area and is a result of the Distribution, discussed in this paper. The third step is called Modal Split or Splitting into transport modes. The mode of transport is predefined by the description of data on the input interface of the system. The Assignment of traffic describes a model to define the routes between the origin and the destination in the network. Even for a single mode of travel, there are often several possible routes between the origin and the destination.

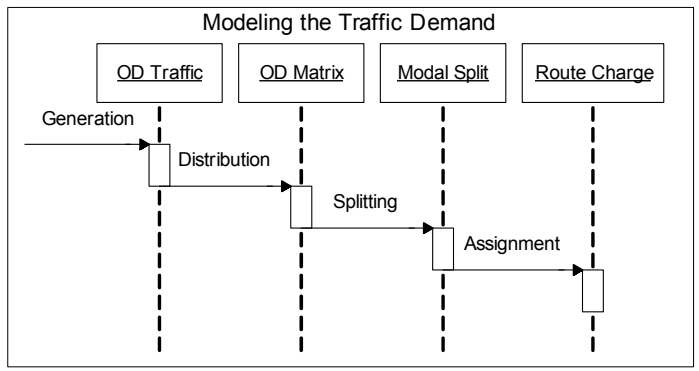

Figure 1: $\quad$ Steps in modelling the traffic demand [1].

\section{Floating car data}

The most common technologies for positioning are satellite-based systems with high accuracy and availability [2]. Positioning Systems with lower requirements 


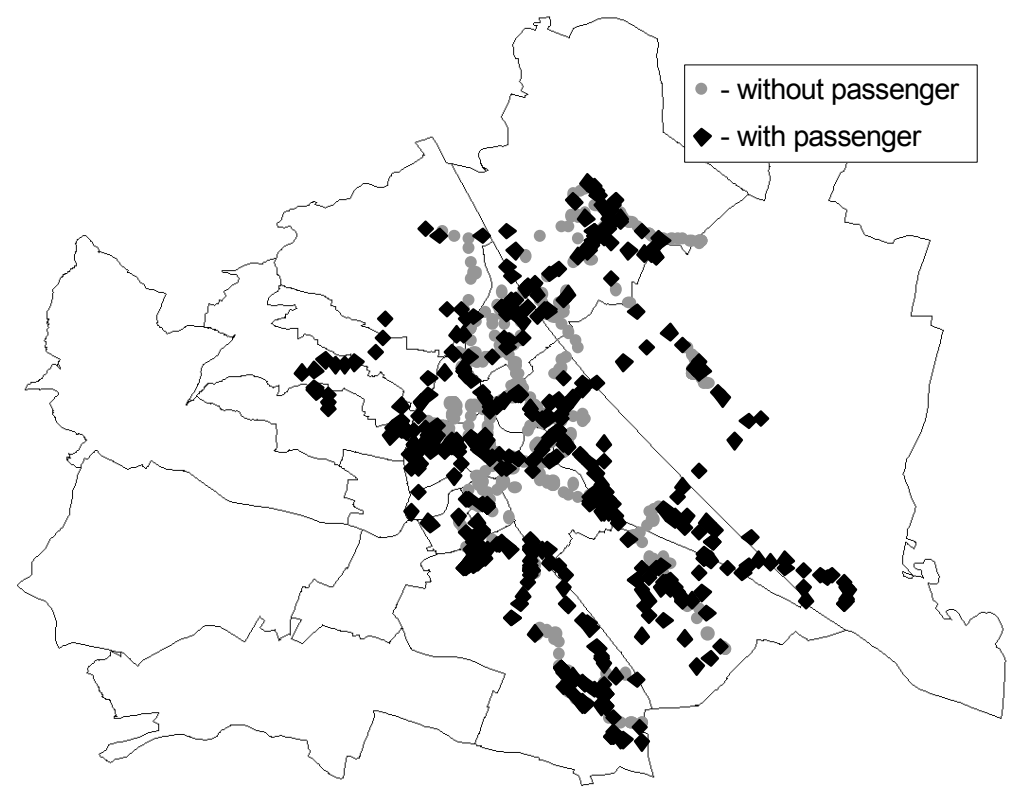

Figure 2: $\quad$ Illustration of taxi FCD (one vehicle, one day).

are often equipped with mobile phone systems, with the advantage of very good network coverage and the possibility to use the same network for data transmission.

The input data for the developed system are derived from a fleet management system for taxi organisation in Vienna. All taxis are equipped with a GPS receiver and a transmitter for communication with the taxi radio system. Figure 2 shows the position data of one vehicle from one day. Within the fleet management system the kind of trip is registered. Only the trips with passengers are used in the system (shown as black squares in figure 2). The numbers of passenger trips are distributed over a day as shown in figure 3.

The typical peaks from rush hour traffic in the morning (7 to $10 \mathrm{am}$ ) and in the evening (14 to $19 \mathrm{pm}$ ) are also identifiable as a high number of trips in the evening and night until 2 am. More than 50 percent of passenger trips take place during the rush hours. The timeseries represents a typical weekday out of holidays.

The traveltime describes the effort in time for a travel from origin to destination. The complex traveltime consists of all possible parts described by eqn (1).

$$
\begin{aligned}
T & =\sum T_{F}+T_{Z}+T_{W}+\sum T_{U W}+T_{S}+T_{A} \\
T & =\sum T_{F}+\sum T_{Z S}
\end{aligned}
$$




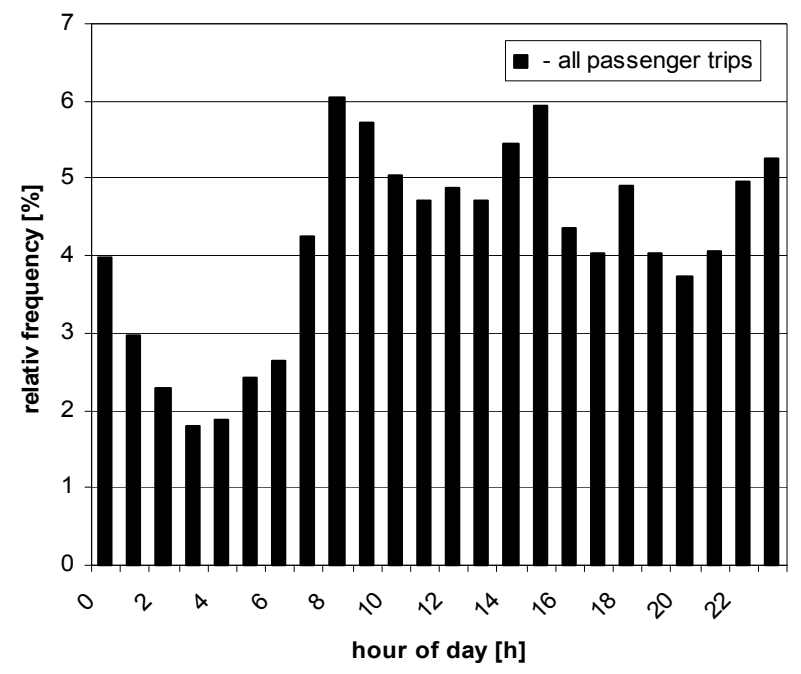

Figure 3: $\quad$ Typical trip distribution over time on a weekday.

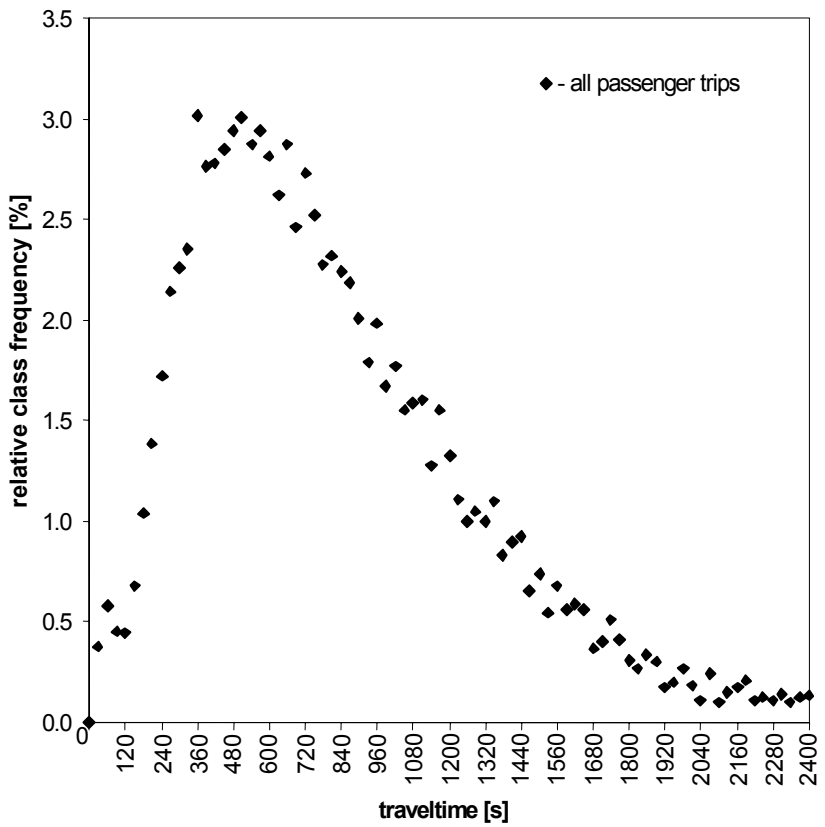

Figure 4: Frequency distribution by traveltime. 
The parts representing access times $\left(\mathrm{T}_{\mathrm{Z}}\right)$, waiting times $\left(\mathrm{T}_{\mathrm{W}}\right)$, times for changing transport $\left(\mathrm{T}_{\mathrm{UW}}\right)$, searching a parking area $\left(\mathrm{T}_{\mathrm{S}}\right)$ and exit times $\left(\mathrm{T}_{\mathrm{A}}\right)$ are merged to a sum of additional times $\left(\mathrm{T}_{\mathrm{ZS}}\right)$ in eqn (2). In the case of Taxi FCD we assume that there are very low waiting times and no additional ways because of the door-to-door service. So we can focus on the times for transport $\left(\mathrm{T}_{\mathrm{F}}\right)$.

Considering the different states of the taxi in the fleet management system the traveltime of typical passenger trips were evaluated. All passenger trips of a typical weekday were assigned to classes in steps of 30 seconds, shown in the frequency distribution in figure 4.

77.8 percent of passenger trips have traveltimes between 2 and 20 minutes. The evaluation of a sample rate has shown that trips with higher traveltimes often have the origin or the destination on the airport, which is reachable in approx. $30 \mathrm{~min}$. from the city centre by car.

Furthermore the OD Matrix in table 4 lists higher percentages for trips within one district, denoting trips with short traveltimes.

\section{System architecture}

The introduced system was designed to evaluate FCD and generate an OD Matrix, the step of Distribution in the process of modelling the traffic demand.

The system functionally is encapsulated in separate commands based on the command design pattern [5]. Figure 2 illustrates the commands and the interaction with data objects and the map. The geographical map is the central component within the system architecture. The FCD available via the import interface is referenced to the geographical map by the component mapmatch. The position data and the direction of driving are taking into account to find the most adequate network link and the position on it. The way from Origin to Destination can be reproduced by the routing component, which is based on an adapted Djikstra algorithm. A coherent route is a required to specify a planned route (see also table 1).

Table 1: $\quad$ Type of trips in the simulation environment.

\begin{tabular}{|c|c|}
\hline Type of trip & Description \\
\hline random trip & A random trip is generated based on turning relations \\
\hline planned trip & The trip is defined by a certain route (often used for public transport) \\
\hline OD trip & $\begin{array}{c}\text { Defined is the origin and destination of the trip, the assignment is } \\
\text { modelled by the simulation environment }\end{array}$ \\
\hline network charge & Random origin and random route choice, used for initial network charge \\
\hline
\end{tabular}

The OD Matrix for the simulation environment is generated by odfilter, considering traffic zones and filter criteria, and provided via the export interface.

\section{Simulation environment}

The system architecture provides an export interface adapted to the data structures of the simulation environment. The simulation environment handles 
microscopic traffic models and manages the data in database files. One of these database files is representing the trips for the traffic demand model.

The different types of trips, available in the simulation environment are listed in table 1. The system architecture was designed to evaluate FCD and generate two types of trips, OD trips and planned trips.

Figure 5 illustrates the GPS position from a typical taxi trip in Vienna, distinguished by the state of the taxi (with/without passenger). Furthermore the difference of a planned trip, representing a route, and an od-trip, defined by origin and destination position, is shown.

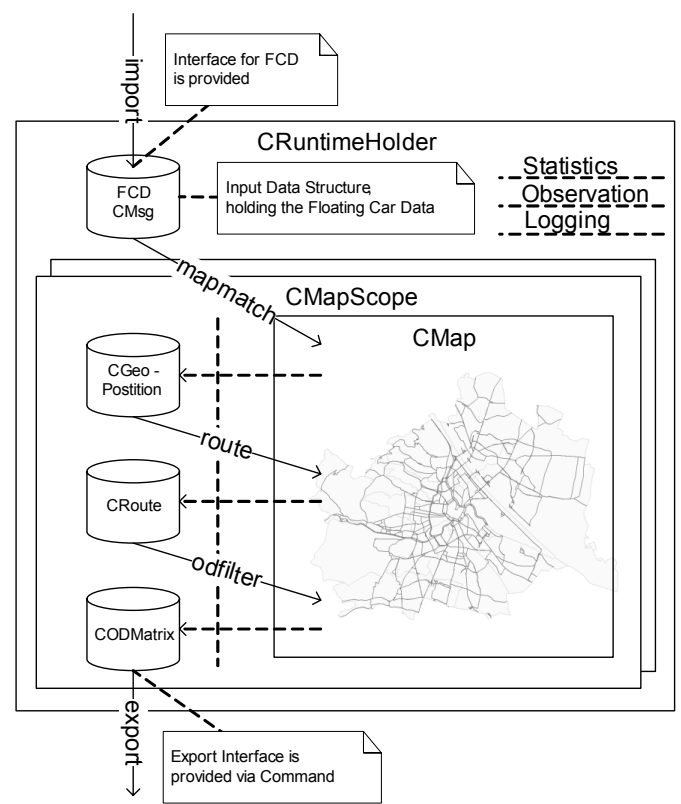

Figure 5: System architecture and component interaction.

\section{Data aggregation}

The determination of traffic flows depends on the arrangement of the planning area into traffic zones. The size of traffic zones is derived with the structure of the area, the available statistics, the number of inhabitants and already existing borders. The traffic between the zones is described as traffic flows represented in OD matrices.

The system can produce OD matrices in different resolution, depending on the size of the planning area and the required result for the traffic model.

Table 2 lists the implemented methods to establish the geographical reference of the trips to the map. The chronological aggregation is based on the definition of scenarios. Every scenario is defined by timestamps for start and end, e.g. to represent the rush hours. 


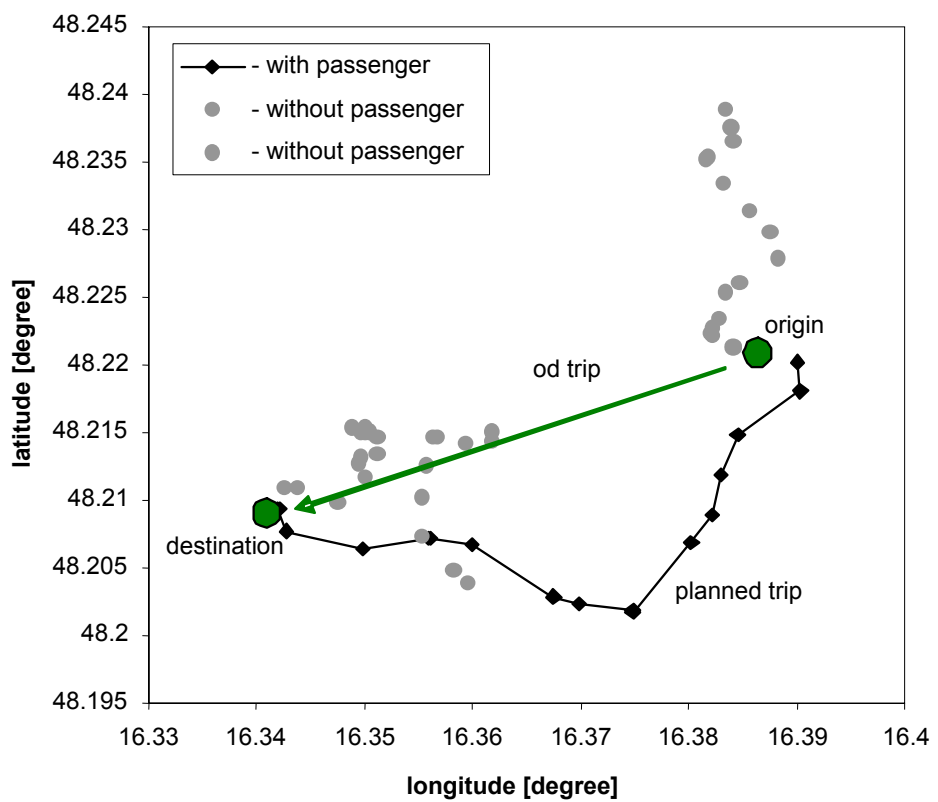

Figure 6: A typical taxi trip, with/without passenger.

Table 2: $\quad$ Available resolution to generate OD matrices.

\begin{tabular}{cccc}
\hline Method/result & Resolution & Input & Simulated trip \\
\hline link & approx. $50 \mathrm{~m}$ & position, heading & od trip, planned trip \\
sector & approx. $300 \mathrm{~m}$ & position & od trip \\
district & approx. $1000 \mathrm{~m}$ & position & od trip \\
\hline
\end{tabular}

\section{Case study and results}

A case study with data from a taxi fleet in Vienna was done for the time period from July to December 2007.

The system was configured to work with the aggregation method for districts. Table 3 represents the OD Matrix from the field trial for the districts 1 to 10. The lines represent the originating districts (index i) and the columns the destination districts (index $j$ ). The matrix is filled with the percentage of trips from district $i$ to $\mathrm{j}$, also called traffic flows $\left(\mathrm{F}_{\mathrm{ij}}\right)$.

$$
\sum_{j=1}^{n} F_{i j}=O_{i} \quad \sum_{i=1}^{n} F_{i j}=D_{j}
$$


Table 3: $\quad$ OD matrix from field trial in Vienna.

\begin{tabular}{c|cccccccccc|c}
$\mathrm{i} j$ & 1 & 2 & 3 & 4 & 5 & 6 & 7 & 8 & 9 & 10 & $\mathrm{Oi}$ \\
\hline 1 & 2.01 & 0.92 & 1.06 & 0.52 & 0.39 & 0.56 & 0.52 & 0.39 & 0.71 & 0.54 & 7.64 \\
2 & 0.97 & 1.31 & 0.51 & 0.15 & 0.13 & 0.18 & 0.17 & 0.13 & 0.30 & 0.25 & 4.11 \\
3 & 1.17 & 0.55 & 1.24 & 0.29 & 0.20 & 0.24 & 0.21 & 0.14 & 0.26 & 0.48 & 4.78 \\
4 & 0.60 & 0.17 & 0.34 & 0.29 & 0.18 & 0.18 & 0.16 & 0.10 & 0.15 & 0.28 & 2.45 \\
5 & 0.40 & 0.14 & 0.22 & 0.19 & 0.38 & 0.20 & 0.16 & 0.08 & 0.12 & 0.38 & 2.27 \\
6 & 0.63 & 0.21 & 0.28 & 0.21 & 0.26 & 0.41 & 0.25 & 0.15 & 0.21 & 0.22 & 2.83 \\
7 & 0.65 & 0.22 & 0.28 & 0.19 & 0.17 & 0.23 & 0.31 & 0.17 & 0.28 & 0.17 & 2.68 \\
8 & 0.45 & 0.14 & 0.18 & 0.11 & 0.09 & 0.14 & 0.16 & 0.15 & 0.20 & 0.11 & 1.72 \\
9 & 0.76 & 0.29 & 0.28 & 0.15 & 0.12 & 0.18 & 0.22 & 0.17 & 0.50 & 0.15 & 2.82 \\
10 & 0.43 & 0.20 & 0.42 & 0.24 & 0.30 & 0.17 & 0.12 & 0.08 & 0.14 & 2.56 & 4.65 \\
\hline Dj & 8.08 & 4.17 & 4.80 & 2.34 & 2.21 & 2.48 & 2.28 & 1.55 & 2.88 & 5.16 & 35.96
\end{tabular}

Classes [\%]: \begin{tabular}{|c|}
\hline $0.0-0.5$ \\
\cline { 2 - 2 } \\
\hline $1.0-2.0$ \\
\hline
\end{tabular}

\begin{tabular}{|c|}
\hline $0.5-1.0$ \\
\hline$>2.0$ \\
\hline
\end{tabular}

The right column and the bottom row in table 3 represent the sums of traffic flows (see also eqn. (3)). The matrix indicates the most trips from and to the districts 1 to 3 , located in the centre of Vienna. Furthermore the highest numbers of trips were determined within one district (e.g. the $1^{\text {st }}$ or $10^{\text {th }}$ district).

The evaluation of trip state is an essentially part to filter non-representative data sets. Only trips initialized by customers are used, because they are representing the needs of the customers. The result of the field trial is an empirical derived OD Matrix, without any extrapolations to the whole motorized individual traffic (MIT).

As expected the results are strong dependent on the kind of FCD and the special behaviour of the fleet. The analysis and first results have shown that taxi fleets have their special attributes, e.g. taxis are driving main districts and public places, like airports, rail stations, hotels or entertainment centres [4].

Best results are expected from FCD with similar distribution as the whole MIT, e.g. by using a sample of mobile phone data. Arsenal research is trying to setup cooperation with mobile phone providers to do further research. The integration of the trip matrix in a simulation tool will help to force the iterative process of reproduction the reality within a traffic model.

\section{References}

[1] Lohse, D., Schnabel, W., Grundlagen der Straßenverkehrstechnik und der Verkehrsplanung, volume 1, Verlag für Bauwesen, Berlin, 1997.

[2] Linauer, M., Schneider, M., Hainitz, N., Mrakotsky, E., Travel Time Estimation based on Real-Time Toll Data in Austria, technical paper, 13th World Congress on ITS, London, 2006

[3] Kwon, J., Varaiya, P., Real-Time Estimation of Origin-Destination Matrices with Partial Trajectories from Electronic Toll Collection Tag Data, 84th Annual Meeting - Transportation Research Board, Washington D. C., 2005 
[4] Linauer, M., Generating and processing of Floating Car Data as a basis for the use in Traffic Telematics Systems, Dissertation, Institute for Transport Studies, University of Natural Resources and Applied Life Sciences, Vienna, 2005

[5] Johnson, R., Gamma, E., Helm, R., Design Pattern - Elemente wiederverwendbarer objektorientierter Software, volume 1, AddisonWesley Verlag, Pearson Education, Deutschland, 2004. 